\title{
EMOCIONES Y CREATIVIDAD: UNA PROPUESTA EDUCATIVA PARA TRABAJAR LA RESOLUCIÓN DE CONFLICTOS EN EDUCACIÓN INFANTIL
}

\author{
Emotions and creativity: an educational proposal for conflict resolution in pre- \\ school education \\ Virginia Guichot-Reina \\ Ana María De la Torre Sierra
}

Fecha de recepción: 22/09/2017

Fecha de aceptación: 06/02/2018

RESUMEN: En las últimas décadas, se ha incrementado el número de investigaciones relacionadas con la conocida como "inteligencia emocional" debido a la constatación de los múltiples beneficios para el individuo de una adecuada educación en este terreno desde la infancia, tantas veces olvidado en la escuela. Las ventajas afectan no solo al plano intrapersonal, sino también al interpersonal, esto es, al de las relaciones con los demás, y permiten el logro de una convivencia dentro de los parámetros de una cultura de la paz. En este trabajo, hemos vinculado la educación emocional con otro término de gran relevancia para la formación integral de la persona: la creatividad. Presentamos una propuesta para fomentar la inteligencia emocional y la resolución pacífica de conflictos a partir del desarrollo del pensamiento flexible y divergente en los niños y niñas, en este caso de la etapa de educación infantil, ya que conviene empezar desde edades tempranas. A partir de los resultados obtenidos tras la implementación de nuestro proyecto en un centro educativo, extraemos algunas conclusiones y animamos a la reflexión sobre aspectos como la necesidad de formación del profesorado en esta temática y las ventajas que el trabajo en Educación Emocional posee para toda la comunidad educativa.

PALABRAS CLAVE: Educación Emocional, Creatividad, Pensamiento divergente, Educación Infantil.

ABSTRACT: Over the last decades, research on emotional intelligence has escalated with ample evidence of multiple benefits for the individuals who make adequate progress on this trait. Emotional intelligence affects not only the intrapersonal level. How people relate to one another -the interpersonal level- is influenced too and with this the development of a culture of peace. In this study, Emotional Education is linked to another term of great relevance for people's integral development: creativity. We present a proposal for the encouragement of Emotional Intelligence and the peaceful resolution of conflicts through the development of flexible and divergent thinking in pre-school students. From the results obtained after the implementation of our project in a public school, located in Seville, we draw some conclusions and encourage reflection on aspects such as the need for teacher training in this area and the advantages that emotional education brings to the entire educational community.

KEYWORDS: Emotional Education, Creativity, Divergent Thinking, Pre-school Education. 


\section{Introducción}

Nuestra actual Constitución española cumple ahora cuarenta años. Aprobada en diciembre de 1978, su artículo 27.2 destaca que "la educación tendrá por objeto el pleno desarrollo de la personalidad humana en el respeto a los principios democráticos de convivencia y a los derechos y libertades fundamentales". Es decir, desde nuestros comienzos como sociedad democrática, tras cuarenta años de dictadura franquista, se subraya en nuestra ley fundamental la necesidad de que la educación proporcione una formación integral de la persona, que atienda a todas las dimensiones del individuo, y que, además, apueste, especialmente, por el logro de una convivencia armónica en una sociedad pluralista, bajo los parámetros de lo que se ha denominado una "cultura de paz" (Jares, 2006). Esta posición, como cabía esperar, se ha mantenido en las diferentes leyes educativas promulgadas bajo la democracia, como la Ley Orgánica 8/1985, de 3 de julio, reguladora del Derecho a la Educación (LODE), la Ley Orgánica 1/1990, de 3 de octubre, de Ordenación General del Sistema Educativo (LOGSE), la Ley Orgánica 2/2006, de 3 de mayo, de Educación (LOE) o la Ley Orgánica 8/2013, de 9 de diciembre, para la Mejora de la Calidad Educativa (LOMCE), actualmente en vigor. Se refuerza, además, por diferentes medidas legislativas y declaraciones institucionales realizadas en el marco de la Unión Europea, en la que España está incluida. Por ejemplo, a partir del término "competencia", que puede ser definido como una combinación de habilidades prácticas, conocimientos, motivación, valores éticos, actitudes, emociones, y otros componentes sociales y de comportamiento que se movilizan conjuntamente para lograr una acción eficaz -tal como lo hizo el Ministerio de Educación, Cultura y Deporte en la Orden ECD/65/2015, de 21 de enero-, la Recomendación 2006/962/EC, del Parlamento Europeo y del Consejo, de 18 de diciembre, habla sobre siete competencias clave y entre ellas incluye las competencias sociales y cívicas, definiéndolas como:

Las competencias sociales y cívicas implican la habilidad y capacidad para utilizar los conocimientos y actitudes sobre la sociedad, entendida desde las diferentes perspectivas, en su concepción dinámica, cambiante y compleja, para interpretar fenómenos y problemas sociales en contextos cada vez más diversificados; para elaborar respuestas, tomar decisiones y resolver conflictos, así como para interactuar con otras personas y grupos conforme a normas basadas en el respeto mutuo y en convicciones democráticas. (p.6998)

Ahora bien, ¿realmente hemos atendido a esta formación integral?; en concreto, ¿estamos educando para el logro de esa convivencia en valores democráticos? Según múltiples investigaciones (Goleman, 1996; Bisquerra, 2000; Darder, 2003; Dettoni, 2014; Extremera y Fernández 2015), no estamos avanzando todo lo que se debiera y, en general, en los sistemas educativos occidentales se continúa dando prioridad al desarrollo de aspectos académicos en el alumnado, vinculados al denominado "coeficiente intelectual". Y ello ocurre, sorprendentemente, a pesar de que dicho nivel intelectual solo garantiza un $20 \%$ del éxito laboral y personal, como subrayó uno de los pioneros en el campo de la inteligencia emocional, Daniel Goleman, hace más de veinte años, en su libro Emotional Intelligence: Why It Can Matter More Than IQ, de 1995. Situaciones complejas a las que nos enfrentamos todos los días, como por ejemplo las que vivimos como conflictivas, exigen al individuo contar con un bagaje de herramientas relacionadas con la gestión de emociones y con el dominio de habilidades sociales que debería ser proporcionado por diferentes agencias educativas, ocupando un lugar privilegiado la escuela.

Entre los múltiples beneficios que aporta la educación emocional se encuentra la potenciación del denominado pensamiento flexible, divergente o creativo, muy apreciado en 
una sociedad como la nuestra, caracterizada por cambios constantes y a un ritmo vertiginoso. Frente a la errónea creencia de que la creatividad es una cualidad que se limita a unas pocas personas, hemos de reivindicar que todos tenemos potencial creativo y que este se puede desarrollar y mejorar, incrementándose así nuestra capacidad de buscar y proponer diferentes soluciones a los problemas (Bisquerra, Pérez y García, 2015).

Este trabajo se centra en analizar la relación existente entre emociones y creatividad y su valiosa contribución para la resolución pacífica de conflictos, fundamental en el camino hacia el desarrollo de una auténtica pedagogía de convivencia democrática. Además, queremos destacar el papel esencial del profesorado en este proceso y, por consiguiente, la necesidad de una adecuada preparación que debe ya incluirse desde su formación inicial. Asimismo, consideramos que la etapa infantil, en la que centramos nuestra propuesta de intervención, es un periodo óptimo para promover el desarrollo emocional de los niños y niñas puesto que creemos que se debe iniciar esta educación desde edades tempranas.

Hemos incluido en este artículo el diseño y la implementación de nuestra propuesta educativa en el segundo ciclo de Educación Infantil (3-6 años) en un colegio público sevillano, ya que permite conocer de primera mano los beneficios que posee la inclusión de las emociones y la creatividad en el desarrollo integral del alumnado, en el bienestar docente y en la convivencia escolar. Terminamos con unas reflexiones finales que pretenden animar al profesorado a dar a la Educación Emocional un papel de primer orden en los procesos formativos que ofrecen a su alumnado.

\section{Aproximación terminológica: Emociones, Inteligencia Emocional, Educación Emocional y Creatividad}

Muchas son las definiciones que se han ido aportando a lo largo de la Historia acerca del término "emoción", relacionándolos con otros como "afecto" o "pasión" y, en general, conceptualizándolo en oposición al de "razón", vinculándose este a vocablos como "cognición", "entendimiento" o "espíritu". Salvo casos excepcionales, no ha sido hasta bien entrado el siglo XX cuando se estableció la íntima vinculación entre razón y emoción que dio lugar a un concepto sobradamente conocido como el de inteligencia emocional. La conciencia de su importancia originó la necesidad de su potenciación, de ahí que se empezara a hablar de una educación emocional que atendiese al logro de ciertas competencias como la regulación y la autonomía emocional, necesarias para una vida sana y una convivencia armónica en las sociedades. Dicha educación se relaciona directamente con el fomento de la creatividad, muy valorada en nuestros días dado el contexto de cambios acelerados y aparición de nuevos problemas que exigen soluciones novedosas. Trataremos someramente estos conceptos que fundamentan nuestro trabajo.

\subsection{Emoción: definición y funciones}

Las emociones son fenómenos o estados que motivan nuestras acciones, por lo que la mayoría de nuestras decisiones y comportamientos tienen origen emocional (Extremera y Fernández, 2015; Fernández-Martínez y Montero-García, 2016). Bisquerra (2000) define el término "emoción" como "un estado complejo del organismo caracterizado por una excitación o perturbación que predispone a una respuesta organizada. Las emociones se generan habitualmente como respuesta a un acontecimiento externo o interno" (p.61). Tal caracterización nos remite al hecho de que las emociones se despiertan a partir de una valoración que realizamos cuando percibimos un hecho o acontecimiento.

Frecuentemente, se confunden los conceptos de "emoción" y "sentimiento", llegando a usarse indiscriminadamente. Por ello, Bisquerra et al. (2015) establecen la siguiente 
distinción: "el componente cognitivo de la emoción coincide con lo que se denomina sentimiento. El sentimiento es la emoción hecha consciente y que con la participación de la voluntad se puede alargar o acortar en el tiempo" (p.129). Asimismo, estos autores añaden que las emociones se dan durante un corto periodo de tiempo mientras que los sentimientos pueden durar más, e incluso toda la vida (ibidem, p.138)

Las emociones juegan un papel de primer orden en nuestras vidas. Maganto y Maganto (2010) señalan cuatro funciones básicas: motivacional, adaptativa o de protección, social e informativa. Poseen una función motivacional y de toma de decisiones ya que preparan y dirigen la conducta potenciando la acción. Además, nos permiten responder a situaciones que nos encontramos diariamente, tanto positivas como negativas, generando cambios en nuestro organismo ante determinados estímulos como medio de protección (función adaptativa o de protección). Por ejemplo, cuando sentimos miedo, nuestra piel se pone pálida debido a que la sangre se retira del rostro y se desplaza a otras zonas del cuerpo, como las piernas, para favorecer la huida y alejarnos del peligro. Las emociones tienen también una función social al facilitar las relaciones sociales y la comunicación de sentimientos. Muy relacionada con esta última utilidad está la función informativa que nos da pistas acerca de cómo se sienten los demás y nos permiten ajustarnos a sus necesidades. Gestos y otras expresiones corporales en general nos informan de las emociones tanto propias como ajenas.

El mundo emocional es complejo y posee muchos matices, por lo que no es de extrañar que existan múltiples formas de clasificar las emociones: positivas y negativas, primarias y secundarias, buenas y malas, etc. (Dettoni, 2014). No obstante, parece haber un consenso generalizado respecto a las emociones conocidas como básicas o primarias, entre las que encontramos: alegría, tristeza, miedo, enfado, asco y sorpresa.

\subsection{Inteligencia Emocional}

Aunque desde la Antigüedad se estudian conceptos cognitivos relacionados con las emociones, será a finales del siglo XX, en concreto, en 1990, cuando nace el concepto de inteligencia emocional de la mano de Peter Salovey y John Mayer. Ambos autores, en una definición de 1997, la describen como:

La Inteligencia Emocional incluye la capacidad para percibir, valorar y expresar emociones con exactitud; la habilidad de acceder a y/o generar sentimientos que faciliten el pensamiento; la habilidad para comprender emociones y el conocimiento emocional; y la capacidad para regular las emociones promoviendo el crecimiento emocional e intelectual. (Salovey y Mayer 1997, p.10)

Salovey y Mayer formulan un modelo de inteligencia emocional de carácter holístico, dado que mezcla tanto aspectos cognitivos como de la personalidad (Bisquerra et al., 2015). Además, conciben la inteligencia emocional como un conjunto de habilidades que unifican razón y emoción, y hacen hincapié en que el pensamiento no existe sin el sentimiento y ambos se retroalimentan (Ruiz et al., 2013). La posesión de altas competencias emocionales posibilita un mejor razonamiento al poder controlar y comprender lo que sentimos, y, además, somos más creativos y flexibles en la búsqueda de soluciones a los problemas (Mayer y Salovey, 1990).

El término inteligencia emocional se popularizó de la mano del psicólogo Daniel Goleman. Para Goleman (1996) la inteligencia emocional se refiere a la capacidad para percibir, comprender, reconocer, valorar, discriminar, identificar y regular las emociones en uno mismo y en los demás, con el objetivo de promover el conocimiento emocional e 
Emociones y creatividad: una propuesta educativa para trabajar la resolución...

intelectual. Está formada por competencias emocionales que implican cinco ámbitos: autoconocimiento, autorregulación, empatía, motivación y habilidades sociales. Dichas competencias se pueden educar y desarrollar mediante experiencias emocionales y sería misión de los distintos agentes educativos, como la familia y la escuela, ocuparse de formarlas. Las ventajas son numerosas: mejora de los resultados académicos, optimización de su adaptación activa al entorno, aumento de la posibilidad de alcanzar sus objetivos vitales, etc. (Mestre y Fernández, 2007).

La educación emocional es una forma de prevenir el analfabetismo emocional, que suele derivar en frustración, estrés y violencia y supone grandes costes humanos y económicos a la sociedad (Bisquerra, 2000). La Educación Emocional jugaría un papel esencial como medida de prevención a través de la aportación de recursos y estrategias para que los seres humanos aprendiesen a gestionar sus emociones y a mantener una actitud positiva hacia la vida. Bisquerra y Pérez (2007) defienden que dicha educación estaría destinada a cubrir cinco competencias emocionales básicas:

- Conciencia emocional. Capacidad que implica el conocimiento de las propias emociones al igual que un uso adecuado del vocabulario emocional. Asimismo, incluye la habilidad para captar e identificar el ambiente emocional y comprender las emociones o estados de ánimo de los demás. Esta capacidad emocional es dividida en dos competencias emocionales por Mestre y Fernández (2007): por un lado, se encuentra el autoconocimiento, donde debemos reconocer nuestras cualidades y fortalezas y cuáles son nuestros sentimientos en cada momento. Por otro lado, tenemos el conocimiento social, competencia con la que apreciamos las emociones de los demás y aprendemos a valorar sus sentimientos.

- Regulación emocional. Capacidad que nos permite controlar nuestras emociones de forma adecuada. Se trata de la competencia que Mestre y Fernández (2007) definen como autogestión, la cual facilita la adquisición de nuestras metas y objetivos. El desarrollo de la regulación emocional depende de factores externos e internos, que aumentarán o no la capacidad de la persona de reflexionar, comprender y decidir sobre sus emociones. Bisquerra, et al. (2015) afirman que regulación no es sinónimo de represión, sino que se trata de canalizar las emociones para alcanzar un equilibrio entre la represión y el descontrol, y no dejarnos llevar por comportamientos impulsivos. Existen diferentes técnicas que nos pueden ayudar a regular nuestras emociones como el diálogo interno, el mindfulness, la atribución causal, etc.

- Autonomía emocional. Incluye la autoestima y responsabilidad sobre nuestros actos, la capacidad de tener una actitud positiva hacia la vida y la capacidad para analizar críticamente las normas sociales.

- Habilidades sociales. Conjunto de capacidades que nos permiten relacionarnos de manera positiva con los demás como, por ejemplo, la escucha activa. Por su parte, Mestre y Fernández (2007), incorporan esta capacidad emocional en la competencia "habilidades de relación", basadas en la comunicación, en compartir emociones, en prevenir, en resolver y en cooperar en la construcción de relaciones. Darder (2003) resume estas habilidades sociales en la empatía, que posibilita reconocer el estado de ánimo de los demás y establecer relaciones respetuosas con los otros.

- Habilidades para la vida y el bienestar. Capacidades que nos permiten adaptarnos a las complejas situaciones de nuestra vida. Implica establecer objetivos, tomar decisiones, etc. Mestre y Fernández (2007) se refieren a esta competencia como toma de decisiones responsable, centrada en el análisis y la solución positiva de problemas. 
El desarrollo de las competencias emocionales posee grandes beneficios en todos los ámbitos: personal, escolar, familiar y social. Fomentan nuestro bienestar y una actitud más positiva ante la vida, reduciendo costes sociales, personales y económicos.

\subsection{Educación Emocional}

Las emociones están presentes en la vida de los seres humanos desde que nacen e intervienen en todos los procesos evolutivos, como en el desarrollo de la personalidad y en la interacción social. Vivimos en un ambiente rodeado de emociones, en el cual hemos de aprender a expresar y controlar las propias, y a comprender y respetar las de los demás (Heras, Cepa y Lapa, 2016). Dentro de los diferentes contextos afectivos en los que va creciendo el individuo, como son el entorno familiar, el entorno escolar y el entorno de las amistades, estos autores inciden en la importancia del ámbito escolar, en el que niños y niñas necesitan sentirse queridos, comprendidos y apoyados. La escuela debe ser un lugar donde se les permita expresarse, crecer emocional y socialmente, y superarse a sí mismos para así favorecer su formación integral. Muchos factores intervienen en la consecución de unos buenos resultados: la relación familia-escuela, la figura del/la docente, el grupo-clase, etc.

Bisquerra (2000) define la Educación Emocional como "un proceso educativo, continuo y permanente, que pretende potenciar el desarrollo emocional como complemento indispensable del desarrollo cognitivo, constituyendo ambos los elementos esenciales del desarrollo de la personalidad integral. Para ello se propone el desarrollo de conocimientos y habilidades" (p.243). La escuela está obligada a promover un modelo educativo que estimule el desarrollo de hábitos emocionales y sociales, en todos los ámbitos del currículum escolar.

Los objetivos generales de la Educación Emocional, basándonos en Bisquerra (2000) y Gardner (2011) son:

- Adquirir un mejor conocimiento de las propias emociones.

- Identificar las emociones de los demás.

- Desarrollar la habilidad para regular las propias emociones.

- Prevenir los efectos nocivos de las emociones negativas.

- Desarrollar la habilidad para generar emociones positivas.

- Desarrollar la habilidad de automotivarse.

- Adoptar una actitud positiva ante la vida.

Son muchos los beneficios que aporta la Educación Emocional al alumnado como el aumento de las habilidades sociales y las relaciones interpersonales satisfactorias; la disminución de la violencia y agresiones; el incremento del rendimiento académico; la mejora de la adaptación escolar, social y familiar; la reducción de la ansiedad y el estrés; entre otros (Gardner, 2011). En definitiva, existen razones de peso para su implementación en las aulas. Ahora bien, es importante que una educación basada en las emociones vaya de la mano de la enseñanza de principios éticos y reglas morales, es decir, de una educación moral. Tal como defienden Fuentes, López, Roselló y Talavera (2003), las emociones son la base de la enseñanza moral. Debemos enseñar a los niños y niñas a utilizar sus competencias emocionales de manera moralmente adecuada y encaminada hacia conductas prosociales, evitando que su habilidad derive en malas acciones. En la escuela, han de favorecerse actividades en las que el alumnado participe en dinámicas de grupo para aprender a ser solidario, a cooperar, a respetar a los demás y las normas sociales.

Con frecuencia, el profesorado se pregunta cuándo es el mejor momento para empezar a trabajar en clase la Educación Emocional. Coincidimos con autores como FernándezMartínez y Montero-García (2016) en que la etapa de Educación Infantil es un momento 
Emociones y creatividad: una propuesta educativa para trabajar la resolución...

óptimo para comenzar a promover el desarrollo emocional de los niños y niñas. A estas edades estamos más conectados a nuestro mundo emocional, por lo que nuestras emociones son mucho más espontáneas y naturales (Fuentes et al., 2003). Desde pequeños debemos aprender a identificar, expresar y controlar lo que sentimos, ya que construir una buena base emocional en este periodo desde la que sustentar todo el aprendizaje futuro genera grandes beneficios en el individuo.

El personal docente es, sin duda, una pieza fundamental en la enseñanza de habilidades emocionales y sociales y el paso previo es que él mismo se encuentre bien formado. La docencia es una actividad profesional que requiere de una fuerte implicación emocional que puede derivar en agotamiento y estrés, principalmente ante la aparición de problemas o conflictos en el aula ("Síndrome del profesor quemado" o "Síndrome Burnout"). Dicho síndrome lleva al docente a sentirse poco realizado y desgastado profesional y personalmente. Por el contrario, el profesorado con altas competencias emocionales desarrolla una actitud más positiva y motivadora hacia su trabajo que beneficia al clima del aula (Extremera y Fernández, 2015).

En esta línea, Bisquerra et al. (2015) exponen diez indicaciones que potencian el desarrollo emocional del profesorado: ser consciente de las emociones propias y las de los demás; contagiar emociones positivas al alumnado; comprender las causas de las emociones; escuchar de forma activa y empática, mostrando apoyo y comprensión a sus alumnos y alumnas; regular y gestionar sus propias emociones en el aula; expresar adecuadamente sus propias emociones; educar desde la compasión, confianza y esperanza; tener una buena autoestima y valorarse positivamente; tolerar emociones como la frustración; y gozar de bienestar personal y profesional. Los maestros y maestras deben ser referentes para su alumnado, expresando y gestionando adecuadamente sus emociones, fomentando el debate, la comunicación, la reflexión, la escucha activa, la confianza, el intercambio de ideas y el trabajo cooperativo ya que, según los investigadores, la actitud del profesorado en el aula parece ser el elemento más importante para favorecer el desarrollo emocional y creativo en los niños y niñas (Marina y Marina, 2013).

\subsection{Creatividad}

Una premisa básica, demostrada por numerosos estudios, es que la creatividad se puede estimular y es educable. Todas las personas estamos dotados de creatividad y la influencia del entorno, al igual que la actitud e interés del propio individuo, determinan su potencial de desarrollo (Rollano, 2004). Desde que nacemos contamos con una serie de cualidades que favorecen el desarrollo de la creatividad, entre las cuales cabe resaltar: la necesidad de investigar, la curiosidad por conocer el mundo, la imaginación, la espontaneidad, etc. (Guzmán, 2015).

Definir el término "creatividad" es una tarea bastante compleja, ya que son muchos los elementos que la componen y tienden a confundirse como: originalidad, imaginación, flexibilidad, pensamiento divergente, innovación, descubrimiento, libertad, sensibilidad, y curiosidad (Ferrándiz, García, y González-Herrero, 2003). En concreto, los conceptos "imaginación” e "innovación” son empleados frecuentemente como sinónimos de creatividad.

No obstante, Ken Robinson, en su obra Busca tu elemento (2012), nos da las claves que diferencian a la creatividad de estos componentes. Por un lado, la imaginación es la base sobre la que se desarrolla nuestro pensamiento creativo: no hay creatividad sin imaginación, esto es, sin la facultad para representar mentalmente sucesos, historias o imágenes de objetos, pero no significan lo mismo. La creatividad conlleva la producción de algo, implica crear, no solo imaginar. En consecuencia, Robinson afirma: "la creatividad es la imaginación aplicada" 
(2012, p.201). Por otra parte, la innovación constituye el siguiente paso de la creatividad, es decir, supone implementar con éxito las ideas novedosas que se generaron y compartirlas con los demás. La creatividad es un proceso crítico donde se elabora algo nuevo o se reelabora algo ya conocido desde un punto de vista diferente y original. Además, no basta con que la idea sea novedosa: ha de ser también útil, eficaz y valiosa (Alexander, 2010). La creatividad no tiene límites y la escuela tendría que ser un lugar estimulante para el niño/a, en el que se le proporcione libertad para que pregunte, investigue, descubra, exprese sus deseos y preocupaciones, etc.

Sin embargo, la relación e influencia que tiene la creatividad en el desarrollo emocional de los niños y niñas ha sido aún poco explorada y hay escasos trabajos que hablen de su implementación en el aula. En concreto, una técnica muy interesante es la que propone Kreidler (1984) llamada sharing circles o círculos de confianza, cuyo objetivo es promover la expresión de sentimientos, emociones y preocupaciones en el alumnado acerca de diferentes temas, siendo conveniente para que sea eficaz una realización diaria. Una buena forma de iniciar estos círculos es empezar por frases como: "cuando estoy enfadado...", "algo que me dio miedo fue...", etc. No hay que forzar al alumnado a participar en este tipo de actividades, por lo que cada estudiante tiene derecho a cederle el turno a otra persona.

Estas indicaciones apuestan por una educación creativa y emocional. A pesar de que se conozcan los beneficios de este tipo de aprendizaje, existe una falta de formación inicial y permanente del profesorado. Hoy en día la escuela continúa centrándose en el desarrollo cognitivo e intelectual, a través de un aprendizaje puramente memorístico y repetitivo (Marina, 2013); predominando así lo que Alexander (2010) denomina como the right answer o la respuesta correcta, en la que se potencia el pensamiento convergente al no permitir que el alumnado busque múltiples soluciones o alternativas a los problemas. En este sentido, el profesorado debe ser motor de cambio, necesita salir de su zona de confort, en la que se sienten seguros y cómodos, para fomentar un aprendizaje basado en el descubrimiento y en la expresión de sentimientos, y en este proceso la educación emocional y la creatividad tienen mucho que decir. Para desarrollar la creatividad en el aula existen diversas estrategias como la técnica del brainstorming o lluvia de ideas, la modificación de ideas, el listado de atributos, etc. (Ferrándiz et al., 2003; Alexander, 2010).

\section{Resolución de conflictos y Educación Emocional}

Los conflictos son situaciones complejas que se presentan diariamente en nuestras vidas. Beltrán y Pérez (2000) dan la siguiente definición: "Un conflicto se suele entender como un desacuerdo o enfrentamiento de valores, opiniones o necesidades entre personas, organizaciones o grupos" (p.218). Son inevitables y consustanciales a nuestra convivencia social, ya que la interacción con otros origina, en ocasiones, que el individuo perciba una incompatibilidad entre el logro de sus propios objetivos y los intereses de los demás (Pérez de Guzmán, Amador y Vargas, 2011). Los conflictos no suponen por sí mismos un problema, siempre que el sujeto sepa responder de manera adecuada a los mismos y los pueda convertir en experiencias valiosas de aprendizaje.

Existen diferentes factores que intervienen en un conflicto y que deben tenerse en cuenta para su resolución. López (2008) propone el llamado mapa del conflicto en el que incluye tres elementos conocidos como las tres " $P$ ": persona, problema y proceso.

- Persona. Señala la necesidad de comprender la percepción individual de cada persona respecto al conflicto, sus emociones, sus sentimientos, sus percepciones, sus valores, sus necesidades, el rol que presenta cada uno dentro de este, etc. 
Emociones y creatividad: una propuesta educativa para trabajar la resolución...

- Problema. Es el asunto en concreto que genera el conflicto, los intereses y diferencias de cada parte (diversos puntos de vista, principios, valores e intereses opuestos, etc.).

- Proceso. Es la forma en la que se toman las decisiones respecto al conflicto y cómo se sienten las personas implicadas, es decir, es la historia del conflicto, la comunicación, la versión de cada parte, etc. Se trata de analizar cómo se ha generado el conflicto.

Examinando estos tres elementos nos damos cuenta de que las competencias emocionales citadas anteriormente posibilitan una correcta resolución del conflicto, por lo que la Educación Emocional resulta un elemento imprescindible para el logro de una convivencia pacífica.

Para trabajar la resolución de conflictos desde la perspectiva de una pedagogía de la convivencia, ésta debe ser planificada en todas las áreas del currículum escolar partiendo de una reflexión sobre el modelo de convivencia deseado. Sin embargo, la formación del profesorado en temas de convivencia y resolución de conflictos continúa siendo bastante limitada. El docente debe procurar dar herramientas al alumnado para que aprenda a solucionar los conflictos por sí mismo y los convierta en oportunidades de crecimiento personal. Los alumnos y alumnas con un mayor desarrollo emocional poseen una imagen ajustada y positiva de sí mismos, tienen una mayor capacidad para resolver problemas interpersonales y son más conscientes de los estados emocionales de los demás, etc. (Giménez, Quintanilla y Daniel, 2013).

La resolución de conflictos es un proceso creativo en el que se pueden combinar diferentes maneras de pensar y actuar. Siguiendo esta línea, Bransford y Stein (1993) propone una serie de indicaciones que nos permiten solucionar los problemas de forma creativa, expuestas en su modelo conocido como IDEAL, formado por las siguientes partes:

Figura 1. Modelo IDEAL para resolver los problemas creativamente

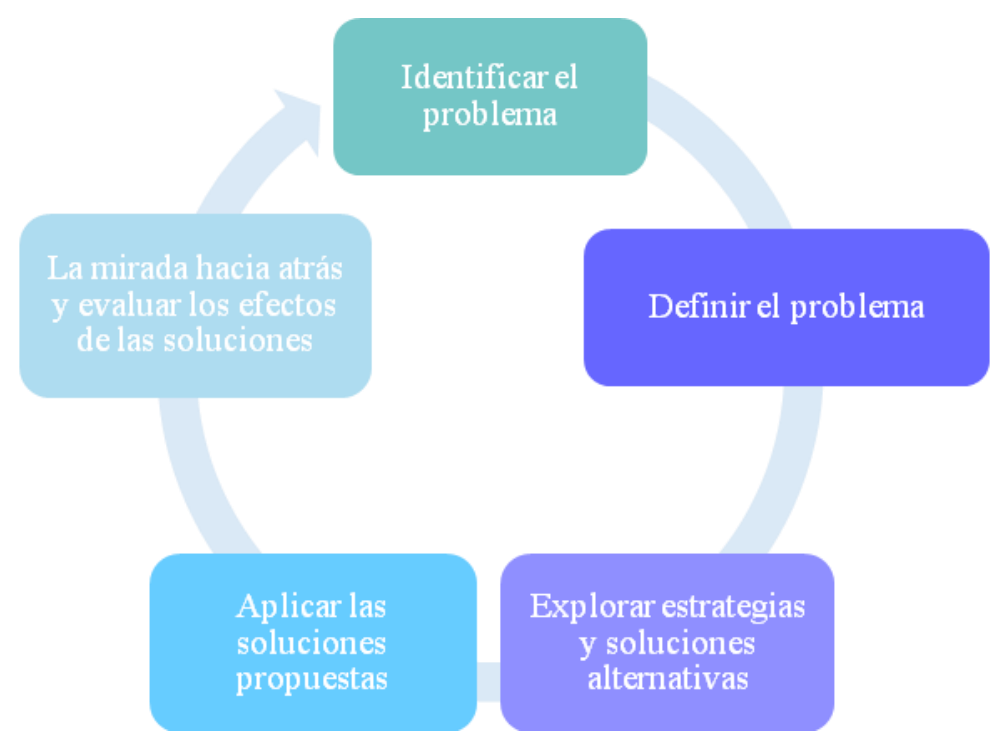

Fuente: Elaboración propia a partir de Bransford y Stein (1993)

La resolución de conflictos de manera creativa aporta muchos beneficios, pero también presenta algunos obstáculos que dificultan su puesta en práctica. Ferrándiz et al. (2003) agrupan estos impedimentos en dos ámbitos: personal y escolar. Por un lado, en los obstáculos personales encontramos los bloqueos mentales (complejidad para limitar el problema, etc.) y bloqueos emocionales (falta de confianza en sí mismo/a, miedo a la opinión de los demás, inseguridad para proponer ideas nuevas, etc.). Por otro lado, en la escuela aparecen ciertas barreras que limitan la libertad, espontaneidad y creatividad del alumnado, 
como, por ejemplo, la potenciación del aprendizaje basado en la repetición, la aceptación o sumisión de normas, etc.

En el aula, los principales conflictos surgen debido al ambiente competitivo, la falta de comunicación, la inadecuada expresión de las emociones, etc. Kreidler (1984) propone diferentes técnicas como el time out o tiempo fuera, en el cual se pide a los niños/as que tienen un conflicto que se desplacen a un punto tranquilo de la clase y se les da tres minutos para que puedan hablar del problema sin ayuda; si no funciona después de ese tiempo el docente debe actuar y escuchar de nuevo el problema como si fuera la primera vez para ayudar a solucionarlo. Para dicho autor, hay cinco elementos básicos que hay que trabajar en el alumnado para el logro de una clase impregnada de una cultura de paz:

1. Cooperación. Aprender a trabajar juntos, a compartir y a ayudarse mutuamente.

2. Comunicación. Aprender a escuchar activamente y a observar el ambiente, para comunicarse de manera adecuada.

3. Tolerancia. Aprender a respetar las opiniones de los demás.

4. Expresión positiva de las emociones. Aprender a expresar lo que sienten, mediante técnicas positivas, en especial el enfado y la frustración (de manera no agresiva), y a regular sus propias emociones.

5. Resolución de conflictos. Aprender las habilidades para responder creativamente a los conflictos.

Es indiscutible la ligazón entre educación emocional y resolución de conflictos. Una sociedad democrática está reclamando que prestemos atención a esa dimensión afectivaemocional tantas veces olvidada o relegada en las escuelas a un segundo plano y que es la base para una convivencia en paz y respetuosa con el pluralismo.

3. Una propuesta educativa para trabajar el desarrollo emocional y creativo en Educación Infantil: El camaleón Ramón

Nuestro proyecto El camaleón Ramón surge como una propuesta educativa para trabajar la Educación Emocional y el desarrollo creativo en el segundo ciclo de Educación Infantil (3-6 años). Principalmente, se propone como objetivo la identificación, comprensión y regulación de las emociones básicas por parte de los niños y niñas en estas edades. De igual forma, pretende favorecer el pensamiento flexible y divergente en el alumnado, partiendo de la búsqueda de diferentes soluciones a situaciones-problema, cercanas a sus intereses y vida cotidiana.

El eje principal del proyecto es la realidad del conflicto, a partir del cual se pueden trabajar una gran cantidad de contenidos como la escucha activa; el reconocimiento y expresión de emociones en uno mismo y en los demás; habilidades sociales como la empatía, el diálogo y el respeto mutuo; o el pensamiento creativo, divergente y crítico. Además, creemos que se consigue aumentar la motivación del alumnado cuando este se siente "importante" al ser el responsable de proponer y analizar diferentes soluciones a los problemas para buscar la respuesta más adecuada. La participación activa de los niños y niñas es fundamental en todo el proceso, por lo que en el aula se promueve un clima positivo, de seguridad y confianza en el que respetar y compartir experiencias emocionales, y trabajar cooperativamente en la resolución pacífica y creativa de conflictos.

No hay que olvidar que, en esta etapa educativa, los conflictos son muy habituales y a diario se generan enfrentamientos. Los niños y niñas a esta edad presentan un fuerte pensamiento egocéntrico y entienden el conflicto como una competición en la que unos ganan 
Emociones y creatividad: una propuesta educativa para trabajar la resolución...

y otros pierden. Una de las mejores formas de afrontar y prevenir los conflictos en el aula es a través de la Educación Emocional.

La intervención de este proyecto se basa en el aprendizaje por descubrimiento, utilizando un enfoque constructivista: los propios niños y niñas construyen, estructuran, elaboran y se responsabilizan de su propio aprendizaje, fomentando así su autonomía, el pensamiento crítico y un aprendizaje significativo. El papel del maestro/a es el de guía del aprendizaje, proporcionando pistas, sugerencias y utilizando estrategias que favorezcan la creatividad.

El proyecto se organiza en diez sesiones de una hora, en las que se agrupan un total de 24 actividades creativas e innovadoras. Las sesiones se dividen en tres grandes bloques: actividades de iniciación ( $1^{\mathrm{a}}$ sesión), actividades de desarrollo $\left(2^{\mathrm{a}}-8^{\mathrm{a}}\right.$ sesión) y actividades de evaluación y profundización $\left(9^{\mathrm{a}}\right.$ y $10^{\mathrm{a}}$ sesión). Así mismo, se sigue el principio de globalización, es decir, se busca trabajar a través de las actividades todas las áreas de Educación Infantil, atendiendo al desarrollo físico, afectivo, social e intelectual de los niños y niñas. Para ello, el juego es uno de los elementos fundamentales al permitir al alumnado a aprender a convivir y a crecer.

El proyecto se ideó para ponerse en práctica en el aula durante dos semanas. A continuación, se muestra la secuenciación de las sesiones junto a los objetivos didácticos del proyecto:

Tabla 1. Secuenciación de las sesiones del proyecto y objetivos

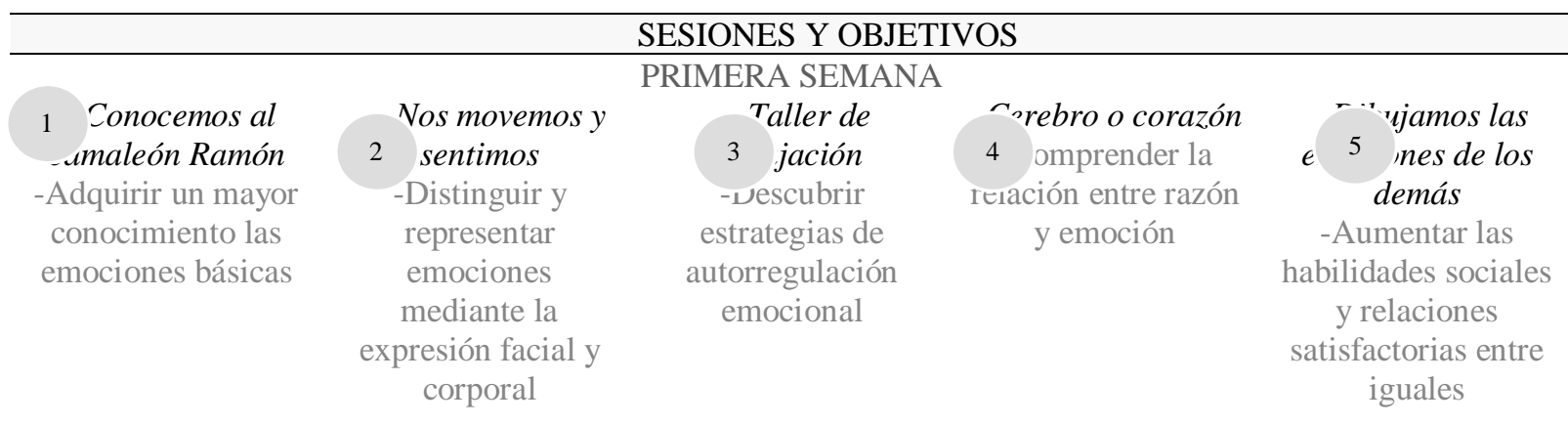

\footnotetext{
6 Lugares y emociones -Compartir experiencias emocionales

Resolviendo
problemas
-Resolver de
manera positiva,
pacífica y
cooperativa
diferentes
conflictos
}

\section{SEGUNDA SEMANA}

$\begin{array}{cccc}\text { Experimentos } & \begin{array}{c}\text { T trivial de las } \\ \text { creativos }\end{array} & \text { Todos valemos } \\ \text {-Conocer } & \text {-Proponer } & \text { Toumentar la } \\ \text { estrategias de } & \text { soluciones creativas } & \text { autoestima y } \\ \text { relajación } & \text { a los problemas } & \text { alumnado }\end{array}$

Fuente: Elaboración propia

El proyecto se puso en práctica en el curso 2016-2017 en un centro público sevillano, el CEIP Jardines del Valle, especialmente interesado en promover el desarrollo integral del alumnado desde la educación emocional. En concreto, las actividades y sesiones se realizaron en el aula de cuatro años, con un total de 27 discentes, 14 niñas y 13 niños.

Los resultados obtenidos han sido muy satisfactorios y se han desarrollado en un clima de clase afectivo y cálido, un ambiente positivo en el alumnado se expresaba libremente, sin vergüenza y respetando los sentimientos y emociones de los demás. Mediante imágenes y 
dibujos empleados en las sesiones, niños y niñas sabían reconocer perfectamente los rasgos faciales de las emociones, pero luego tenían bastantes dificultades para exteriorizarlas y representarlas. De igual modo, la mayoría de estudiantes contaban con habilidades emocionales que les permitían identificar lo que sentían en cada momento, mas no sabían justificar por qué se sentían así. Esta dificultad fue trabajada a lo largo de todo el proyecto, incorporando en la rutina diaria la actividad titulada "El mural de las emociones", demostrando que desde muy pequeños y pequeñas son capaces de aprender a comprender sus propios sentimientos y de expresarlos de manera oral. Al mismo tiempo que identificaban con mayor facilidad el origen de sus emociones y comportamientos, fueron dándose cuenta de cómo podían cambiar sus sentimientos a lo largo del día. Otro aspecto a destacar ha sido el aumento del interés del alumnado por conocer lo que sienten los demás y, lo que es más importante, por descubrir qué podemos hacer para ayudarles a que se sientan mejor, comprendiendo cómo podemos influir en el estado emocional de los demás.

Centrándonos en el desarrollo del pensamiento flexible y creativo, se pusieron en práctica actividades en las que el alumnado debía proponer diferentes soluciones a conflictos, pudiéndose comprobar una evolución en el número de opciones propuestas. Además, su habilidad para analizar los pros y contras de las propuestas también ha progresado. Para conseguir este éxito consideramos que ha sido fundamental la selección de las situaciones conflictivas. En su mayoría, se trataban de casos muy cercanos al interés y a la vida cotidiana del alumnado. Igualmente, habían vivido experiencias previas parecidas, por lo que se les hacía más fácil empatizar con los protagonistas de las historias y proponer ideas para resolverlas.

En definitiva, las actividades del proyecto han contado con una gran implicación por parte del grupo-clase. El clima del aula ha mejorado al igual que las relaciones interpersonales, gracias al fomento del trabajado cooperativo y la resolución pacífica y creativa de conflictos.

\section{Conclusiones}

La Educación Emocional posee importantes beneficios para el desarrollo personal y social y uno de los más destacados es conseguir mejorar la convivencia, posibilitando la incorporación de una serie de competencias al bagaje individual que posibilitan la resolución de conflictos en los parámetros de una cultura de paz. Sin embargo, el sistema educativo español actual no le da la importancia que merece y una muestra de ello es la casi nula inclusión en los planes de estudio de los grados de magisterio y la poca oferta de cursos como formación continua. Sin profesorado bien preparado, es imposible poner en práctica una Educación Emocional y creativa de calidad, en la que los docentes deberían de actuar como modelo. Deberían desarrollar su propia inteligencia emocional, lo que implica manifestar sus propios sentimientos en el aula, compartirlos con el alumnado, interesarse por las emociones de los niños y niñas, aplicar estrategias de autorregulación emocional, etc.

Las emociones y la creatividad deben ser el objetivo principal de enseñanza, ya que permite formar a personas competentes, capaces de regular sus emociones, de enfrentarse a los retos de este mundo globalizado y de resolver los problemas de manera diferente. El alumnado debe aprender a explorar, a investigar, a debatir, a trabajar en equipo, etc., especialmente en las etapas educativas más tempranas, en las cuales se asientan la base de los futuros aprendizajes.

Hemos comentado brevemente los resultados de un proyecto específico, pero la educación emocional debería estar incluida en el aula de una manera globalizada y continua. Cualquier actividad como un cuento o una asamblea es oportuna para trabajar las 
Emociones y creatividad: una propuesta educativa para trabajar la resolución...

competencias emocionales. Como docentes debemos de encontrar la forma más adecuada de integrar las emociones en nuestro día a día, tratando de que se adapte a las necesidades del aula y a los intereses del alumnado, aunque sin duda la mejor herramienta será la que nos proporcione la experiencia.

\section{Referencias bibliográficas}

Alexander, G. (2010). Can We Teach for Surprise? En C. J. Craig y L. F. Deretchin (Ed.), Cultivating Curious and Creative Minds. The role of Teachers and Teacher Educators. Part I: Teacher Education Yearbook XVIII (pp. 24-66). Plymouth, United Kingdom: Rowman \& Littlefield Publishers.

Beltrán, J. y Pérez, L. (2000). Educar para el S.XXI. Crecer, pensar y convivir en familia. Madrid: CCS.

Bisquerra, R. (2000). Educación Emocional y bienestar. Barcelona: Praxis

Bisquerra, R. y Pérez, N. (2007). Las competencias emocionales. Revista Educación XXI, 10, 61-82.

Bisquerra, R., Pérez, J. y García, E. (2015). Inteligencia emocional en educación. Madrid: Síntesis.

Bransford, J. D., y Stein, B. S. (1993). Ideal Problem Solver. New York: W.H. Freeman and Company.

Darder, P. (2003). Las emociones y la educación. En S. Arànega (Ed.), Emociones y educación. Qué son y cómo intervenir desde la escuela (pp. 11-16). Barcelona: GRAÓ.

Dettoni, P. (2014). La inteligencia del corazón. Educar tus emociones. Barcelona: Ediciones Destino.

Extremera, N. y Fernández, P. (2015). Inteligencia Emocional y Educación. Madrid: Grupo 5.

Fernández-Martínez, A. M. y Montero-García, I. (2016). Aportes para la educación de la Inteligencia Emocional desde la Educación Infantil. Revista Latinoamericana de Ciencias Sociales, Niñez y Juventud, 14(1), 53-66.

Ferrándiz, C., García, J. A. y González-Herrero, E. (2003). Creatividad y contexto. En M. D. Prieto, O. López y C. Ferrándiz (Ed.), La creatividad en el contexto escolar. Estrategias para favorecerla (pp.67-97) Madrid: Pirámide.

Fuentes, M., López, M., Roselló, R. y Talavera, M. (2003). La Educación Emocional en la escuela infantil (0-3 años). En S. Arànega (Ed.), Emociones y educación. Qué son y cómo intervenir desde la escuela (pp. 41-47). Barcelona: GRAÓ.

Fuquen, M. (2003). Los conflictos y las formas alternativas de resolución. Revista Tábula Rasa, (1), 265-278.

Gardner, H. (2011). Inteligencias múltiples. La teoría en la práctica. Barcelona: Paidós.

Giménez, M., Quintanilla, L. y Daniel, M. F. (2013). Improving Emotion Comprehension and Social Skills in Early Childhood through Philosophy for Children. Revista Childhood and Philosophy, 9(17), 63-89.

Goleman, D. (1996). Inteligencia emocional. Barcelona: Kairós. 
Goleman, D. (1995). Emotional Intelligence: Why It Can Matter More Than IQ. New York: Bantam Books.

Guzmán, B. (2015). Niños exploradores, niños creativos. Cómo fomentar la creatividad en los niños. Madrid: Kolima.

Heras, D., Cepa, A. y Lara, O. (2016). Desarrollo Emocional en la Infancia. Estudio sobre las competencias emocionales de niños y niñas. Revista de Psicología, 1(1), 67-74.

Jares, X. (2006). Pedagogía de la convivencia. Barcelona: Graò.

Kreidler, W. J. (1984). Creative conflict resolution: more than 200 activities for keeping peace in the classroom. Tucson, USA: Good Year Books.

López, T. A. (2008). Gestión de conflictos: Reflexiones para mejorar nuestra habilidad social de prevenir, manejar y transformar los conflictos interpersonales. $\quad$ Recuperado de http://www.lopezaso.com/Archivos/4gestiondeconflictos.pdf

Maganto, C. y Maganto, J. M. (2010). Cómo potenciar las emociones positivas y afrontar las negativas. Madrid: Pirámide.

Marina, J. A. (2013). El aprendizaje de la creatividad. Recuperado de http://www.joseantoniomarina.net/articulo/el-aprendizaje-de-la-creatividad/ Marina

Marina, J. A. y Marina, E. (2013). El aprendizaje de la creatividad. Barcelona: Ariel.

Mayer, J. D. y Salovey, P. (1990). Emotional Intelligence. Revista Imagination, Cognition, and Personality, 9, 185-211.

Mayer, J. D. y Salovey, P. (1997). What is Emotional Intelligence? En P. Salovey y D. Sluyter (Ed.), Emotional Development and Emotional Intelligence. New York, USA: Basic Books.

Mestre J. y Fernández, P. (2007). Manual de inteligencia emocional. Madrid: Pirámide.

Pérez de Guzmán, V., Amador, L., y Vargas, M. (2011). Resolución de conflictos en las aulas: un análisis desde la Investigación-Acción. Revista Interuniversitaria, (18), 99114.

Robinson, K. (2012). Busca tu elemento. Aprender a ser creativo individual y colectivamente. Barcelona: Empresa Activa.

Rollano, D. (2004). Educación plástica y artística en educación infantil: una metodología para el desarrollo de la creatividad. Vigo: Ideaspropias 